\title{
Selected Risk Factors and Pattern of Semen Abnormality in Male Partners of Infertile Couples in Eastern Nepal: A Descriptive Cross- sectional Study
}

\author{
Sita Pokhrel,' Ashima Ghimire,' Manisha Chhetry, 'Sabina Lamichane, ${ }^{1}$ Rupesh Kumar Shreewastav ${ }^{2}$ \\ 'Department of Obstetrics and Gynecology, Nobel Medical College Teaching Hospital, Biratnagar, Nepal, ${ }^{2}$ Department \\ of Biochemistry, Nobel Medical College Teaching Hospital, Biratnagar, Nepal.
}

Introduction: Semen analysis is an initial basic step in evaluating and diagnosing male infertility. Multiple risks factors in combination or alone are responsible for abnormal semen parameters. The present study aimed to study certain risk factors and semen parameters of infertile male.

Methods: It was a descriptive cross-sectional study. We consecutively enrolled 186 male partners of infertile couple who underwent certain risk factors evaluation and semen analysis according to WHO guideline.

Results: Multiple risk factors were present like Gulf country migration, smoking, chemical exposure and heat exposure in infertile male partners. Forty six percent of our patients were gulf workers. Eleven percent patients had azoospermia, $27 \%$ had abnormal sperm morphology and $23 \%$ had $<25 \%$ motile spermatozoa.

Conclusions: Surprisingly nearly half of our patients were Gulf country workers and abnormal semen analysis is very important factor for infertility. Large prospective studies need to be carried out involving Gulf migrant workers only.

Keywords: infertility; risk factors; semen abnormality parameters.

\section{INTRODUCTION}

In our male dominated society, the blame for infertility goes more to female partners and they suffer from domestic violence, economic deprivation, social neglect, separation and mental trauma. ${ }^{1,2}$ If different parameters of semen analysis are interpreted with clinical profile of the male partner it would give more information for proper future management. ${ }^{3}$

Functional competence of the spermatozoa may be associated with certain semen parameters. ${ }^{4}$ Different studies showed that causes of infertility is attributed to female in $1 / 3^{\text {rd }}$ of cases, male in $1 / 3^{\text {rd }}$ and unexplained in $1 / 3^{\text {rd }} .{ }^{5}$ Factors like diabetes mellitus, chronic medication and disease, psychological factors, chronic alcohol consumption of alcohol, smoking, adverse occupation, nutritional factors and infections play role..$^{6,7}$

Therefore, we wanted to look into the patterns of semen parameters and certain risk factors associated with abnormality in male partners of infertile couple in our setting. It will help to understand the real pattern and parameters of investigation.

Correspondence: Dr. Sita Pokhrel, Department of Obstetrics and Gynecology, Nobel Medical College Teaching Hospital, Biratnagar, Nepal, Email: sitap661@gmail.com, Phone: +9779842396305. 


\section{METHODS}

This was a descriptive cross-sectional study of the certain risk factors and seminal fluid indices of consecutively consenting male partners of infertile couples seen in the department of Obstetrics and Gynecology, Nobel Medical College Teaching Hospital, Biratnagar. The cases were male partner of a couple, who visited the department for infertility treatment in the period of $22^{\text {nd }}$ January 2017 to $21^{\text {st }}$ January 2018. The purpose of the study was explained to the couple, who agreed to be the part of the study was included. The study was carried out after getting the approval of Institutional Review Committee.

We recorded important risk factors and semen parameters in a structured proforma. Information related to risk factors and semen parameters were noted. The male partners were adequately counseled and given instructions on how to collect the semen samples. These instructions included abstinence from coitus for 3-5 days, washing their hands before starting masturbation, sample collection by masturbation only accepted and kept close to the body and delivered to the laboratory within 30 minutes of collection. Spilled samples were avoided. All samples were collected into sterile screw capped plastic universal containers. The semen samples were collected in a dedicated room with bed and other facilities to make them relax within the laboratory and analysed within one hour of collection.

The semen analysis was performed according to the methods and standard outlined by WHO guideline. The sample analysis was done by same laboratory scientist to avoid inter-personal variations. Semen analysis was done within one hour of their collection and was assessed for volume, appearance, liquefaction, concentration, motility, morphology, viability and presence of pus cells. The descriptive statistical analysis was done.

\section{RESULTS}

During the year 2017-2018, a total of 196 couple attended Gynecological OPD for infertility problems and consecutively entered in our study. Out of them three couple did not turn up with investigations report and seven of male partners refused to go for investigation. So, only 186 cases were analyzed in result. Mean age of the male was $28.3 \pm 5$ years. Majority 130 (69.8\%) had duration of infertility $\leq 5$ years followed by $5-10$ years $40(21.2 \%)$ and only $17(9.1 \%)$ had $\geq 10$ years. Majority had secondary infertility. Different risk factors like (Mumps, diabetes, heat exposure, chemicals, Gulf country work etc) have been found to affect semen pattern and parameters adversely in our study. The numbers of patients suffered with mumps in the past that involved testis and found to be infertile were 5 . Similarly, the patients exposed to heat exposure, chemical exposure, involved in smoking, consuming alcohol, suffering with diabetes mellitus, having hydrocele, varicocele and working in Gulf countries with infertility were 9,14, 14,18,9,6,2,5 and 86 in our study as shown (Table 1). The most striking fact of this study is the maximum number of patients with infertility was from group of patients, who were working abroad Gulf countries.

\begin{tabular}{|c|c|}
\hline Main Risk Factors & n (\%) of Partners \\
\hline Golf worker & $86(46.2)$ \\
\hline No risk Facors & $35(18.8)$ \\
\hline Smoking & $18(9.6)$ \\
\hline Chemicals Exposure & $11(5.9)$ \\
\hline Heat exposure & $9(4.8)$ \\
\hline Alcohol & $9(4.8)$ \\
\hline Diabetes Mellitus & $6(3.2)$ \\
\hline Mumps & $5(2.7)$ \\
\hline Varicocele & $5(2.7)$ \\
\hline Hydrocele & $2(1.1)$ \\
\hline Total & $186(100)$ \\
\hline
\end{tabular}

Different parameters of the sperm were analyzed. These included volume, count, motility, morphology and pus cells. Culture of the semen of all the 186 patients was done. In our study, it was found that 101 (54.3\%) patients had less than $2 \mathrm{ml}$ of semen volume. Similarly, the number of patients, who had semen volume 2-4 $\mathrm{ml}$ and more than $4 \mathrm{ml}$ were $83(44.6 \%)$ and $2(1.1 \%)$ respectively as shown (Table 2 ). While analyzing the count, it was found that $21(11.2 \%)$ patients had azospermia in our study. Similarly, 60 (32.25\%) patients were having more than 60 million sperm per $\mathrm{ml}$ as shown (Figure 1).

\begin{tabular}{|lc|}
\hline $\begin{array}{l}\text { Table 2. Distribution of different characteristics of } \\
\text { semen of male partners }(\mathbf{n}=\mathbf{1 8 6}) \text {. }\end{array}$ \\
\hline $\begin{array}{l}\mathbf{n}(\%) \text { of male } \\
\text { partners }\end{array}$ \\
$\begin{array}{l}\text { Morphology of spermatozoa } \\
\text { Normal }\end{array}$ \\
$\begin{array}{l}\text { Abnormal } \\
\text { Number of pus cells/hpf }\end{array}$ \\
$>5$ & $135(72.5)$ \\
Absent & $53(28.5)$
\end{tabular}




\begin{tabular}{|ll|}
\hline $\begin{array}{l}\text { Volume of semen } \\
<2 \mathrm{ml}\end{array}$ & $101(54.3)$ \\
$2-4 \mathrm{ml}$ & $83(44.6)$ \\
$>4 \mathrm{ml}$ & $2(1.1)$ \\
\hline
\end{tabular}

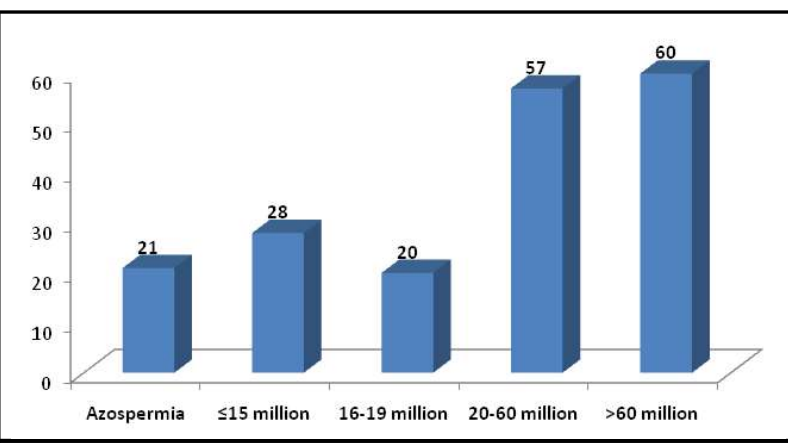

Figure 1. Distribution of Count of Spermatozoa of male partners.

Our study found that $135(72.5 \%)$ males had normal spermatozoa morphology and the rest were found to be abnormal as shown (Table 1). Forty three $(23.11 \%$ ) patients had less than $25 \%$ motile spermatozoa and only $11(5.91 \%)$ patients had $75-100 \%$ motile spermatozoa as shown (Figure 2$)$. In $133(71.5 \%)$ semen samples had more than 5 pus cells per high power field as shown (Table 1).

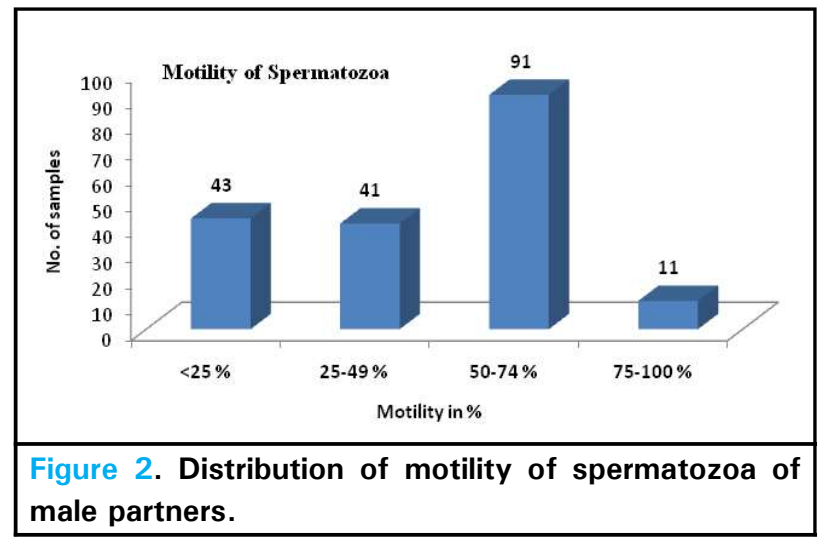

Semen was also looked for the presence of organism by culture of the all samples. Forty eight $(25.8 \%)$ semen samples showed the growth of organism in which $E$. Coli was isolated in $32(17.2 \%)$ cases, S. Aureus in $12(6.45 \%)$ and Proteus in $4(2.15 \%)$ as shown (Figure $3)$.

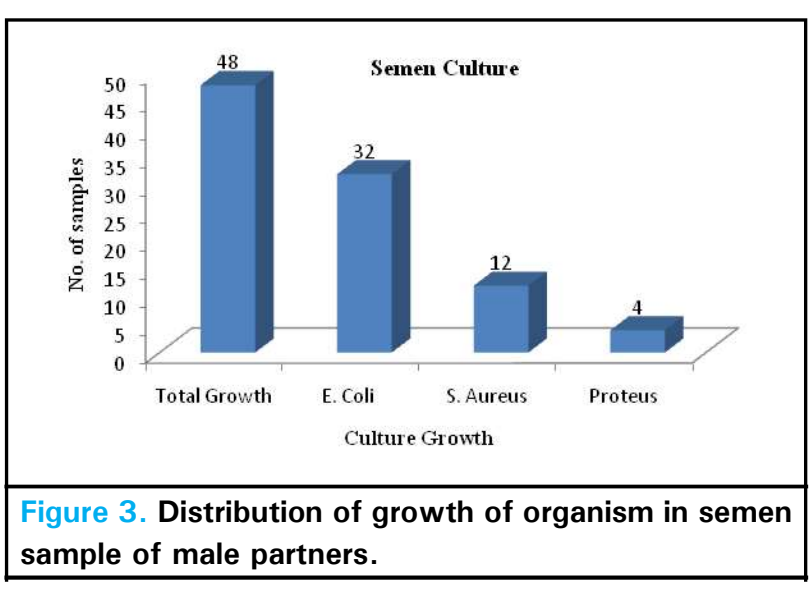

\section{DISCUSSION}

During the analysis of the 186 male partners of infertile couples, we found the average age is $28 \pm 5$ years which are similar with the study done in India. ${ }^{8}$ Majority of our patients had secondary infertility and sought medical help earlier than 5 years this may be because of the family pressure to have next child earlier, want to have next child when female is still young a, need of a friend to previous child and thinking that too much age gap between children makes couple difficult to care them properly. We found many risk factors like chronic smoking, alcohol abuse, diabetes, chemical exposure and other surgical interventions affecting the sperm quality and parameters. Above factors may adversely affect male fertility and surgical interventions may damage vas deference and vascular supply to the testis. Chronic smokers have high risk of infertility and toxins in tobacco smoke may kill sperms. ${ }^{9,10}$ Nine patients some from automobile garage who were mechanics and helpers, others were drivers who were constantly exposed to the heat coming from machines and vehicle engine respectively attended our clinic. We presume that this constant heat exposure to testis in association with other factors contributed to abnormal semen parameters in this group of patients. Many studies have shown that a $1-1.5^{\circ} \mathrm{C}$ increase in scrotal temperature leads to either impaired sperm production or abnormal sperm morphology. ${ }^{11,12}$ Epidemiological studies have revealed that more and more infertile men suffer from acute or chronic inflammation like mumps and chronic chemical exposure of the genitourinary tract, which often occurs without any symptoms. ${ }^{13}$ Chronic alcohol consumption causes sperm parameter abnormalities. ${ }^{14}$ It is very surprising that majority of the couple who sought medical help for infertility had their male partner worked in Gulf countries in the past. There may be multiple reasons behind this. The risk factors like severe stress, effect of climate change, sleeplessness, shift in working hours, exposure to high ambient and work place temperature, long sexual abstinence, adverse housing and work place situation and many others. 
These factors, in susceptible person, may induce or precipitate organic and functional illnesses on top of the high temperature. The high temperature alone or in association with other risk factors may induce sperm parameter abnormalities which in turn lead to infertility. These issues should be addressed with large prospective studies involving migrant workers alone.

In analyzing the semen parameters, Eleven percent of our patients have azoospermia, $55 \%$ of the patients have sperm counts less than 60 million per ml. Absent and low sperm count is associated with male infertility. ${ }^{15}$ The sperm counts of male are declined with time. ${ }^{16}$ Forty five percent of our patients have sperm motility of less than $50 \%$. The World Health Organization (WHO). ${ }^{17}$ Standards of normal sperm indicate that motility value should be greater than or equal to $50 \%$ with forward progression within 60 minutes of ejaculation. Low sperm motility is associated with infertility. ${ }^{15}$ Nearly one third of the males have abnormal sperm morphology which may have negative impact on fertility.

\section{CONCLUSIONS}

To conclude with, multiple risk factors alone or in combination act to cause abnormal sperm parameters. One of our prominent finding is excessive exposure to heat in Gulf migrant workers that lead to abnormal sperm parameters. We found that abnormal semen analysis is the significant contributor to male infertility.

\section{Conflict of Interest: None.}

\section{REFERENCES}

1. United Nations, 1993. 48/104: Declaration on the Elimination of Violence Against Women (A/RES/48/104); and United Nations. 1996. The Beijing Declaration and the Platform for Action: Fourth World Conference on Women: Beijing, China: 4-15 September 1995 (DPI/1766/Wom), paras. 114-116. [․ㅡll Text]

2. Umeora OJ, Igberase GO, Okogbenin SA, Obu ID. Cultural misconception and emotional burdenof infertility in south-East Nigeria. The internet journal of Gynaecol Obset. 2009;10(2):7p. [Full Text]

3. Shaikh AH, Khalique K, Tanq G, Soomro N. Pattern of semen abnormalities in couples with male factor infertility. Pak J Surg. 2011;27(3):204-8. [Full Text]

4. Yamasaki K, Yoshida K, Yoshiike M, Shimada K, Nishiyama H, Takamizawa S, Kaoru Yanagida K, Iwamoto T. Relationship between Semenogelins bound to human sperm and other semen parameters and pregnancy outcomes. Basic Clin Androl. 2017;27:15. [Full Text]

5. Kumar N, Singh AK. Trends of male factor infertility, an important cause of infertility: A review of literature. J Hum Reprod Sci. 2015; 8(4): 191-6. [Full Text]

6. Sharpe RM. Environmental/lifestyle effects on spermatogenesis, Philosophical transactions of the Royal Society of London. 2010;365(1546):1697-712. [ [Full Text]

7. Miyamoto T, Tsujimura A, Miyagawa Y, Koh E, Namiki $\mathrm{M}$, Sengoku K. Male Infertility and its Causes in Human, Adv Urol. 2012;2012:384520. [PubMed]

8. Jajoo S, Kalyani KR. Prevalence of abnormal semen analysis in patients of infertility at a rural setup in Central India. Int J Reprod Contracept Obstet Gynecol. 2013;2(2):161-4. [Full Text]
9. Tong VT, Jones JR, Dietz PM, D'Angelo D, Bombard JM. Trends in smoking before, during, and after pregnancyPregnancy Risk Assessment Monitoring System (PRAMS), United States, 31 sites, 2000-2005. MMWR Surveill Summ. 2009 May 29;58(4):1-31. [PubMed]

10. Agrawal A,Prabhakaran SA, Said TM. Prevention of oxidative stress injury to sperm. J Androl. 2005;26(6):654-60. [PubMed]

11. Bedford J, Berrios M, Dryden G. Biology of the scrotum IV, Testis location and temperature sensitivity. J Exp Zool. 1982; 224: 379-388. [Full Text]

12. R. Mieusset, L. Bujan, A. Mansat, H. Grandjean, F. Po ntonnier. Heat induced inhibition of spermatogenesis in man. Adv Exp Med Biol. 1991;286:233-7. [PubMed]

13. Azenabor A, Ekun AO, Akinloye O. Impact of Inflammation on Male Reproductive Tract. J Reprod Infertil. 2015;16(3):123-9. [PubMed]

14. Vignera SL, Condorelli RA,BalerciaG,Vicari, ECalogero AE. Does alcohol have any effect on male reproductive function? A review of literature. Asian J Androl. 2013;15(2):221-5. [PubMed]

15. Feng HL, Molecular biology of male infertility. Arch Adndrol. 2003;49:19-27. [PubMed]

16. Geoffroy-Siraudin C, Loundou AD, Romain F, Achard V, Courbiere B, Perrard MH, Durand P, Guichaoua MR. Decline of semen quality among 10932 males consulting for couple infertility over a 20 -year period in Marseille, France. Asian Journal of Andrology. 2012 Jul;14(4):584-90. [Full Text]

17. Kamada M, Yamano S,Senuma M, Nakagawa K, Maegawa M, Aono T. Semen analysis and antisperm antibody. Arch Androl. 1998 Mar-Apr;40:117-28. [PubMed]

\section{The Author(s) 2018.}

This work is licensed under a Creative Commons Attribution 4.0 International License. The images or other third party material in this article are included in the article's Creative Commons license, unless indicated otherwise in the credit line; if the material is not included under the Creative Commons license, users will need to obtain permission from the license holder to reproduce the material. To view a copy of this license, visit http://creativecommons.org/licenses/by/4.0/ 